\title{
Justification Embodiments Hose\&Torus Trenchless Technology Pipeline Rehabilitation
}

\author{
Aleksander A. Azeev* \\ Siberian Federal University \\ 79 Svobodny, Krasnoyarsk, 660041, Russia
}

Received 09.04.2015, received in revised form 10.09.2015, accepted 07.10.2015

Based on the analysis of factors influencing the efficiency of pipeline rehabilitation for hose-andtorus technologies and relying on data theoretical and experimental studies of hose-toroidal unit, offers the most efficient method of increasing the efficiency of trenchless work in the formation of composite membranes, as well as ways of its improvement.

Keywords: hose \& torus technologies, trenchless repairs, composite shell.

DOI: $10.17516 / 1999-494 X-2015-8-7-957-963$.

\section{Обоснование вариантов реализации \\ рукавно-торовой бестраншейной технологии \\ восстановления трубопроводов}

\author{
А.А. Азеев \\ Сибирский федеральный университет \\ Россия, 660041, Красноярск, пр. Свободный, 79
}

На основе анализа факторов, влияющих на эффективность восстановления трубопроводов по рукавно-торовой технологии и опираясь на данные теоретических и экспериментальных исследований рукавно-торового агрегата, предлагается наиболее рациональный метод повышения эффективности бестраншейных работ при формировании композиционных оболочек, а также пути его дальнейтего совершенствования.

Ключевые слова: рукавно-торовая технология, бестраншейный ремонт, композиционные оболочки.

(c) Siberian Federal University. All rights reserved

* Corresponding author E-mail address: 3-a@li.ru 


\section{Введение}

В условиях повышения износа трубопроводных систем и нарастания темпов подземного строительства инженерных сетей актуальность повышения эффективности применения бестраншейных технологий не вызывает сомнений. Одним из перспективных бестраншейных способов восстановления и упрочнения трубопроводов и трубных сооружений является рукавно-торовая технология. Несмотря на нарастающую популярность данной технологии, в настоящее время каких-либо упорядоченных сведений для полноценного применения всех ее возможностей не обнаружено. В связи с этим есть потребность систематизации основных вариантов реализации рукавно-торовой технологии.

\section{Результаты и их обсуждение}

Для повышения эффективности применения рукавно-торовой технологии необходимо систематизировать основные варианты ее реализации, определить по совокупности достоинств наиболее перспективный из них и выявить основные ограничения.

На основе результатов патентных исследований, обобщения производственного опыта и с учётом известных классификаций [1-3] составлена уточнённая и дополненная классификация способов бестраншейного ремонта и замены трубопроводов, представленная на рис. 1 . Целесообразность использования того или иного способа будет зависеть от его ограничений, определяемых характеристиками трубопровода, используемыми материалами и экономической эффективностью. Ниже приведены основные бестраншейные технологии.

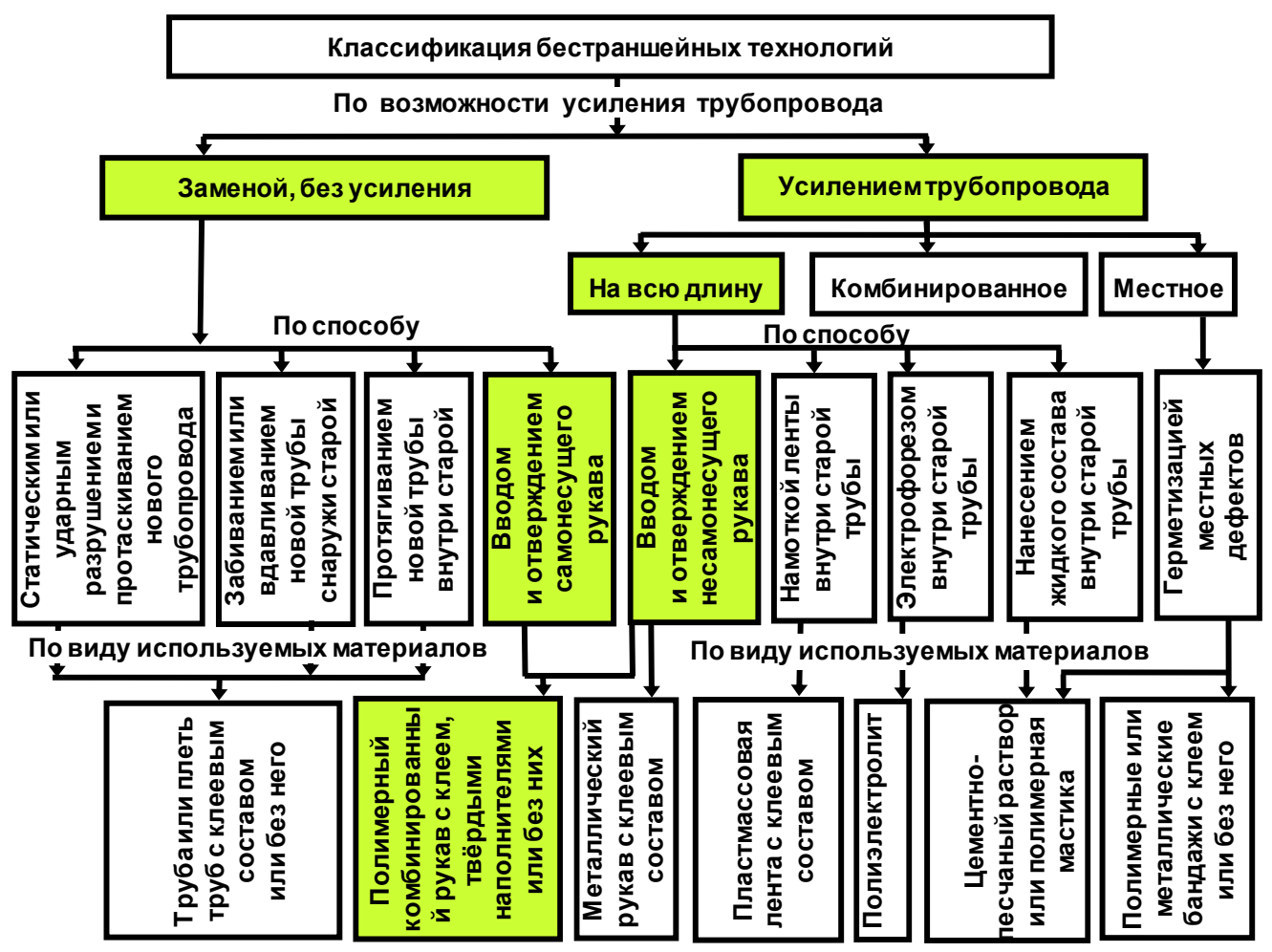

Рис. 1. Классификация бестраншейных технологий 
В приведенной классификации заштрихованы классы, относящиеся к технологии нанесения сплошных рукавных оболочек или рукавно-торовой технологии. Основные преимущества данной технологии: высокое качество и долговечность защитного покрытия; возможность ремонта достаточно изношенных трубопроводов из различных материалов, диаметров, длин и геометрической формы; лёгкость транспортирования сложенной оболочки; возможность ремонта участков горизонтальных и вертикальных трубопроводов с отводами; отсутствие необходимости в ремонте зданий из-за ремонта трубопроводов. Сущность этих технологий связана с вводом внутрь предварительно очищенного трубопровода гибкой синтетической оболочки, пропитанной полимерным компаундом, которая затем полимеризуется. Толщина оболочки в зависимости от диаметра трубы и эксплуатационного давления колеблется от 5 до 25 мм. Благодаря этому после отверждения полимерной композиции в трубе образуется жесткая несущая конструкция, не требующая обязательного приклеивания к стенкам трубы. Для выполнения работ по данной технологии необходимы: оборудование для подготовки места установки оболочки; ТВ-камера; парогенератор или ультрафиолетовый облучатель, агрегат для подготовки и ввода оболочки в трубопровод.

Известно несколько вариантов реализации операций ввода рукавной оболочки в трубопровод (рис. 2) [4-18].

Требуемая толщина покрытия внутри трубопровода может быть образована за один проход рукава («однопроходный» ввод) или за несколько («многопроходный» ввод) (рис. 2). В первом случае при нанесении покрытия, имеющего многослойную армирующую основу, рукав сразу, до ввода в трубу, формируют с нужным количеством слоёв с пропиткой полимерным составом. Преимуществами этого способа является отсутствие необходимости разделения операций по вводу различных слоёв и возможность изготовления рукава в стационарных условиях. К недостаткам относится длительность и даже невозможность быстрой пропитки толстых многослойных рукавов, потребность в больших технологических давлениях для его выворота, а также небольшая длина захватки из-за увеличенного времени пропитки при ограниченной жизнеспособности состава и значительной массы таких рукавов. Именно поэтому такой выворот чаще применяют для однослойных рукавов или мягких и тонких многослойных. Данный

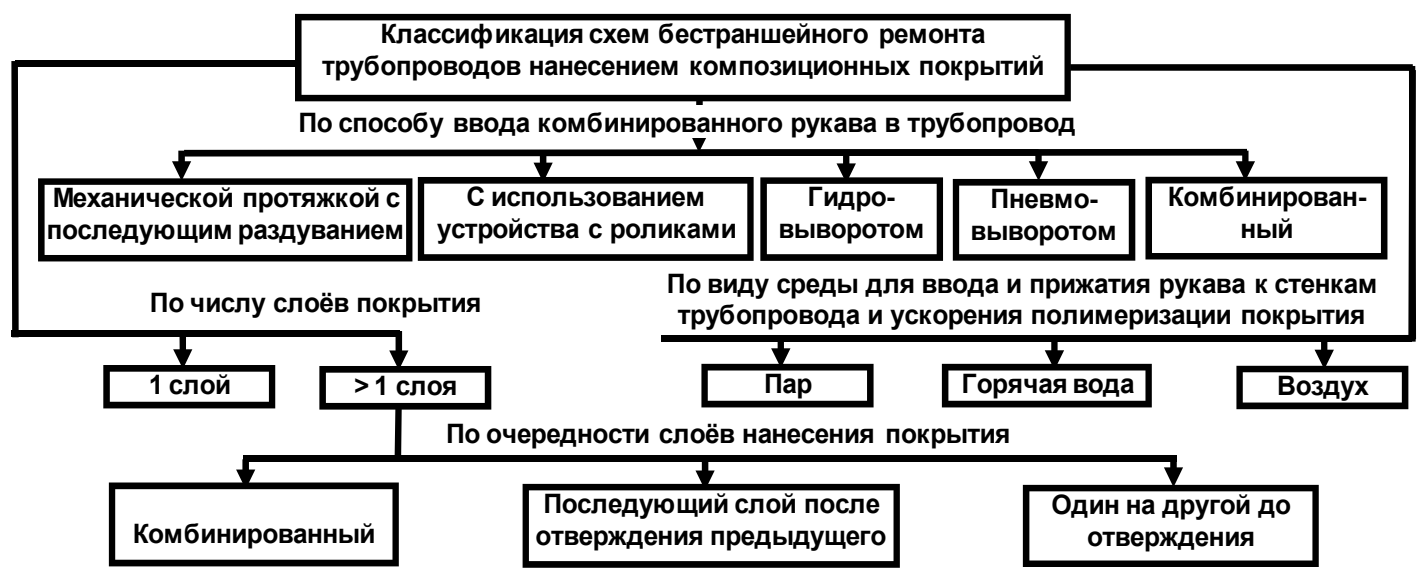

Рис. 2. Классификация видов операций ввода рукавной оболочки в трубопровод

$$
-959-
$$


способ ввода можно назвать «параллельным», так как связан с запараллеливанием операций пропитки и ввода нескольких рукавов одновременно.

Противоположностью «параллельного» выступает «последовательный» ввод, когда после ввода предыдущего слоя начинают вводить последующий либо сразу до отверждения предыдущего, либо после его отверждения. Этот метод устраняет недостатки «параллельного однопроходного» ввода, однако по сравнению с ним требует проведения бо́льшего количества операций и исключает возможность подготовки рукава вне объекта ремонта с последующей его доставкой в рефрижераторе, о чем более подробно далее. Перечисленные методы могут также использоваться в комбинации для достижения нужного эффекта, например при реализации «многопроходного параллельно-последовательного» ввода.

Технологические схемы реализации рассматриваемого способа как в объектных, так и с выполнением части операций в стационарных условиях показаны на рис. 3 .

Преимуществом выворота перед прямой протяжкой является возможность наносить покрытия на более протяжённые участки трубопровода. Это связано с тем, что при вывороте оболочки наизнанку та ее часть, которая вывернулась и прижалась к внутренней поверхности трубопровода, перестает оказывать влияние на тяговое усилие для продвижения остальной невывернутой части. Таким образом, силы трения перемещающейся по трубе сложенной невывернутой части рукава изменяются пропорционально его перемещению с убыванием ближе к середине трубопровода. Эти обстоятельства позволяют выделить способ нанесения покрытия выворотом как более перспективный для восстановления протяженных захваток трубопровода, так как при протяжке оболочки без выворота силы трения возрастают пропорционально длине захватки (рис. 4).

Наибольшее практическое применение нашли два способа выворота рукава в трубопровод - столбом жидкости и сжатым воздухом. Метод ввода оболочки столбом жидкости широко используется рядом западно-европейских фирм, в частности Preussag Rohrsanierung, Per Aarsleff, Le Joint Jnterne, Insituform, National liner и др. В области бестраншейного ремонта путём инверсии оболочки сжатым воздухом работают компании Германии, США и других стран

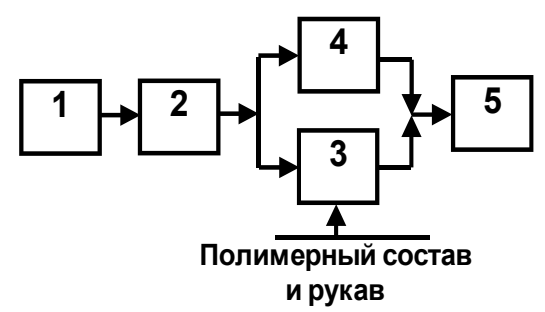

a)

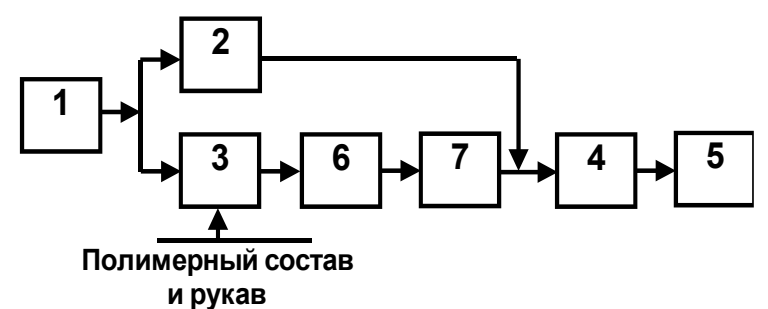

б)

Рис. 3. Технологические схемы реализации рукавно-торовой технологии: $a-c$ выполнением всех работ на объекте; $\sigma$ - с выполнением части работ в стационарных условиях; 1 - заготовка материалов, подготовка площадки, расстановка оборудования; 2 - очистка трубопровода; 3 - пропитка рукава полимерным составом; 4 - ввод рукава в трубопровод, выдержка по времени до окончания полимеризации клея; 5 испытание отремонтированного участка трубопровода и сдача его заказчику; 6 - намотка рукава на съемный барабан или его укладка в поддон со льдом; 7 - транспортирование пропитанного клеем рукава в рефрижераторе при пониженной температуре 
(PRS Rohrsanierung GmbH, Trelleborg epros GmbH, Clean Water Works Inc.). Результаты анализа перечисленных выше способов даны в табл. 1.

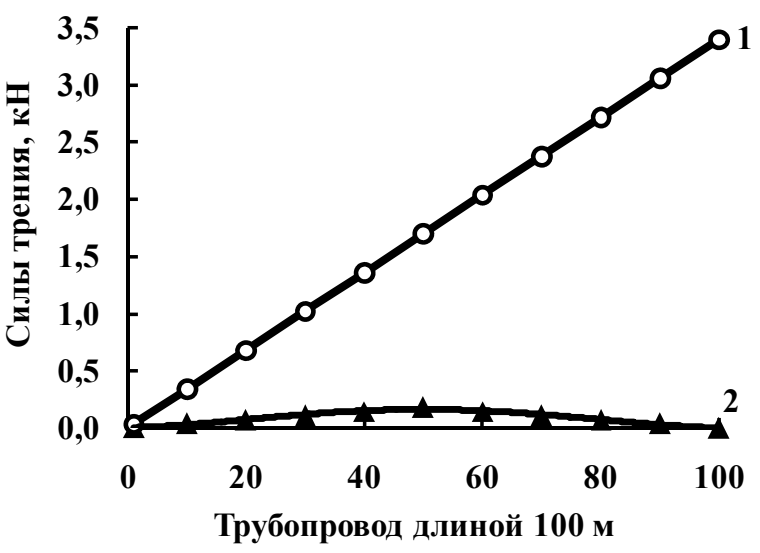

Рис. 4. Изменение сил трения, возникающих при протяжке рукавной (1) и вывороте рукавно-торовой (2) оболочек в трубопроводе длиной 100 м

Таблица 1. Сравнение основных схем ввода рукавной оболочки в трубопровод

\begin{tabular}{|c|c|c|c|c|}
\hline \multirow[b]{3}{*}{ Достоинства способов } & \multicolumn{4}{|c|}{ Наименование способов } \\
\hline & \multicolumn{3}{|c|}{ Выворот рукава } & \multirow[b]{2}{*}{$\begin{array}{l}\text { Прямая } \\
\text { протяжка } \\
\text { рукава }\end{array}$} \\
\hline & 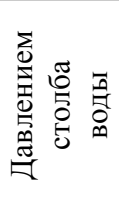 & 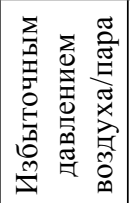 & 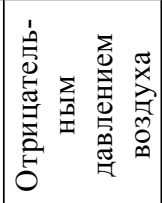 & \\
\hline $\begin{array}{l}\text { - Возможность восстановления трубопроводов со } \\
\text { сквозными отверстиями }\end{array}$ & + & + & - & + \\
\hline - Возможность ввода жестких и толстых рукавов за 1 проход & - & + & - & + \\
\hline $\begin{array}{l}\text { • Возможность восстановления протяжённых участков } \\
\text { трубопровода }\end{array}$ & + & + & + & - \\
\hline $\begin{array}{l}\text { - Возможность восстановления участков с перепадами } \\
\text { по высоте }\end{array}$ & - & + & + & + \\
\hline $\begin{array}{l}\text { - Возможность ввода без истирания клеевого состава } \\
\text { о поверхность трубопровода }\end{array}$ & + & + & + & - \\
\hline • Простота применения и обслуживания оборудования & - & - & + & + \\
\hline $\begin{array}{l}\text { • Наличие резервов для улучшения показателей качества } \\
\text { покрытия с одновременным повышением скорости процесса } \\
\text { ввода рукава }\end{array}$ & + & + & + & - \\
\hline • Возможность одновременного ввода и прижатия рукава & + & + & + & - \\
\hline $\begin{array}{l}\text { - Возможность размещения всего оборудования со стороны } \\
\text { входного колодца (приямка) }\end{array}$ & + & + & - & - \\
\hline • Преодоление отводов & + & + & + & - \\
\hline • Относительно небольшая стоимость реализации & - & + & + & + \\
\hline
\end{tabular}




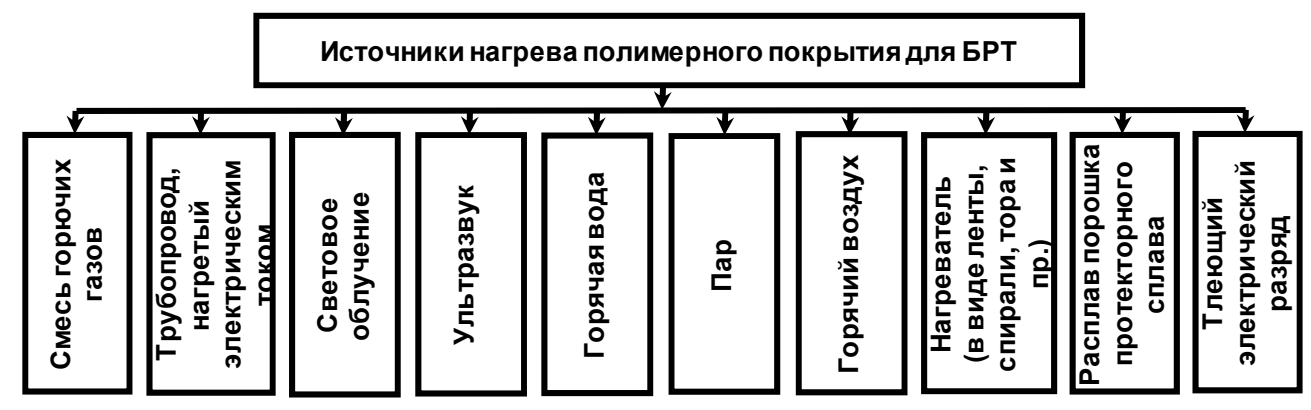

Рис. 5. Классификация источников нагрева полимерного покрытия для бестраншейного ремонта трубопроводов

В патентных источниках и рекламных каталогах зарубежных фирм [4-6, 8-12, 19, 20] упоминается о применении в различных технологиях компаундов как горячего, так и холодного отверждения преимущественно из полиэфирных (ПН-1) и эпоксидных (ЭД-20) смол или их зарубежных аналогов, смол из натурального каучука со стекловолокнистыми включениями, а также клеёв Спрут-4У, 5М и 9М. Каждому полимерному составу соответствует своя совокупность источников нагрева (рис. 5).

Из перечисленных на рис. 5 источников нагрева следует отметить световое облучение, используемое в хорошо себя зарекомендовавшей технологии Berolina-Liner (Германия) при восстановлении водоотводящих дюкеров, в которой применяется двухслойный бесшовный рукав и особая смола с натуральным каучуком, моментально отверждаемая интенсивным ультрафиолетовым излучением с длиной волны 365-420 нм. Данная технология, вероятно, имеет хорошую перспективу на будущее, так как имеет наиболее короткое время реализации заключительных операций.

Из приведённых результатов анализа видно, что способ пневмовыворота рукава избыточным давлением воздуха с ультрафиолетовой системой отверждения обладает наибольшим количеством достоинств. Ограничения рукавно-торовой технологии связаны с невозможностью исправления структурных дефектов трубопровода, невысоким качеством в области переходов и отводов, необходимостью в предварительной подготовке места установки оболочки, потребностью в рефрижераторах для транспортирования охлаждённой оболочки, необходимостью в специально обученном персонале. Таким образом, с учетом данных ограничений и представленных основных возможностей рукавно-торовой технологии можно более обоснованно подходить к планированию производства работ в каждом конкретном случае, а также вести поиск путей дальнейшего совершенствования.

\section{Список литературы}

[1] Емелин В., Шайхадинов А. Бестраншейный ремонт трубопроводов статическим способом с увеличением их диаметра. Красноярск: СФУ, 2007. 240 с.

[2] Продоус О. // ТИЭ. 2003. Вып. 2. С. 19.

[3] Емелин В., Авдеев Р. // ВКГТУ. 2000. Вып. 21. С. 90.

[4] Пат. 4685983 (1987). США // С. А. 1984. № 645123. 
[5] Пат. 5816293 (1998). США // С. А. 1997. N 576527.

[6] Пат. 2006/0093436 (2006). США // С. А. 2004. № 10/904197.

[7] Пат. 2006/0197262 (2006). США // С. А. 2005. № 11/072015.

[8] Пат. 2007/0095472 (2007). США // С. А. 2006. № 11/586128.

[9] Пат. 2007/0204952 (2007). США // С. А. 2007. № 11/747652.

[10] Пат. 2107216 (1998). Россия // 1996. С1.

[11] Пат. 2141072 (1999). Россия // 1997. С1.

[12] Пат. 2167362 (2001). Россия // 2000. С1.

[13] Белобородов В., Ли А., Емелин В. Отечественные бестраншейные технологии восстановления трубопроводов. Красноярск: СФУ, 2010. 220 с.

[14] Храменков С., Орлов В., Харькин В. Технологии восстановления подземных трубопроводов бестраншейными методами. АСВ, 2004. 240 с.

[15] Пат. 2177102 (2001). Россия // 2000. С1.

[16] Пат. 2286506 (2006). Россия // 30. 2004. C1.

[17] Пат. 75448 (2008). Россия // 22. 2008. U1.

[18] Пат. 2278315 (2006). Россия // 17. 2004. С2.

[19] Пат. 2198341 (2003). Россия // 4. 2001. С1.

[20] Пат. 2248497 (2005). Россия // 8. 2003. C1. 